\title{
Stand up for the rights of professors too
}

Sir - I have seen many letters in your pages, most recently from Eugen Tarnow (Nature 398, 657; 1999), suggesting solutions to the problem of supervisors and others unworthily attaching their names to the work of young scientists. But the opposite frequently occurs, so in seeking a solution the pendulum should not swing too far the other way.

In my field, senior scientists might be principal investigators for large space experiments requiring a decade or more of soul-destroying effort. At the end of that time there is usually a flood of new data which investigators and their students and postdocs analyse and publish, generally with the investigator's name attached in recognition that their data are being presented for the first time, whether or not they participated in the analysis. I am sure that analogous situations exist in most research disciplines.

The problem arises when the newcomer publishes such data under their sole authorship, leaving bereft the principal investigator and others in the team, who may be under as much pressure as the youngster to show proof of research activity. Of course, a professor might be in a better position than a student to avoid abuse, but this is not always as easy as might be assumed.

In one extreme example, one of our students provided me with a slide for a presentation that had been emblazoned with her personal copyright statement in large red letters. More commonly, I see papers submitted for publication without the names of those whose significant, unpublished output I know they have used.

The best safeguard against either problem is the integrity of those involved. But students and postdocs can sometimes be poor judges of what is appropriate, and should not be too strongly encouraged to feel they are being exploited when they may just be being nurtured.

\section{F. W. Taylor}

Atmospheric, Oceanic and Planetary Physics, Clarendon Laboratory, University of Oxford, Parks Road, Oxford OX1 3PU, UK

\section{Grim reality of war... and plans for the peace}

Sir - I was amused, in a grim sort of way, to read that scientists in Serbia have asked their colleagues in universities of NATO countries to oppose the bombardment of Serbia and Kosovo (Nature 398, 549; 1999). They point out that many Serb scientists opposed the Milosevic government's attack on the independence of their universities, and helped to force it to accept defeat in elections in 1996.

Well, good for them. But from this report it does not seem that they understand the reason for the NATO onslaught, which has nothing to do with the independence of their universities or the validity of their election process. The reason is the Milosevic government's pursuit of the evil policy of 'ethnic cleansing', the worst offence against humanity in Europe since Hitler's 'ethnic cleansing' of the Jews.

I am not a scientist, but I am opposed to the NATO bombing campaign. I hope that the scientists in Serbia are in turn opposed to the Milosevic government's actions against the Kosovo Albanians.

\section{Ian Blake}

Nibelungengasse 1, Vienna, Austria

Sir - Your report has reinforced my feeling that as scientists we need to show solidarity towards our colleagues in Serbia.

I think that a website should be set up where scientists could exchange views on the role they could play during this terrible crisis. And a fund of money and/or equipment should be donated to Serb scientists when the war is over. Presumably, basic research will not receive priority in the reconstruction of the country.
At times like this, even simple actions can relieve some of the pain. I would be happy to volunteer to assist in these tasks. Stefano Casalotti

Institute of Laryngology and Otology,

University College London,

330 Gray's Inn Road, London WC1X 8EE, UK

\section{Cancer fellowships awarded on merit}

Sir - Stefano Parodi claims that he was treated unfairly by the fellowship selection committee of the International Agency for Research on Cancer (IARC) (Nature 398, $455 ; 1999)$. I served on the committee for many years, and I can report that it ranks its candidates as accurately as possible.

For example, it checks that there is no temporal trend in marking during the course of the two-day meeting, and that the final ranking is not significantly altered if the lowest and highest marks for each candidate are excluded (to avoid strategic marking). Lastly, the cut-off point for awarding fellowships is made where a significant gap in marks separates neighbouring candidates.

The real constraint is that there is only enough money to fund about $20 \%$ of candidates, even though, in my opinion, many show more promise than I did at their age. Parodi wants to see the list of candidates and their scores. That would be most improper. Would he really want his own name and score to be made public? John Cairns

Clinical Trial Service Unit, Radcliffe Infirmary, Harkness Building, Oxford OX2 6HE, UK

Sir - The IARC programme of research training fellowships began in 1967, since when some 500 fellowships have been awarded (http://www.iarc.fr). The selection procedure aims to choose the most talented fellows, based on scientific merit.

After an interview of the candidate and a review of the application, priority scores are assigned by each member of the selection committee, which is an international group of 12 distinguished scientists with expertise in various cancer research disciplines. Some $10-12$ of the $50-60$ candidates evaluated each year are awarded fellowships, based on their average priority scores and the availability of funds. This process takes about four months, and all the candidates are informed soon after.

Parodi was interviewed by an epidemiologist speaking his native language, and an expert biostatistician reviewed his application. He was not among those selected, nor did he qualify as an alternative in the event of an award not being accepted. The selection committee met on 23-24 April 1998, and the candidate was notified of its decision by e-mail, fax and mail by the second week of May.

In June, he requested the list of all candidates, showing who had been accepted, the scores assigned, the reasons for exclusion and the criteria employed. We felt that it would be inappropriate to disclose this, and we are not aware of any fellowship programme that divulges such confidential data.

Ruggero Montesano

Cancer Research Fellowship Programme, International Agency for Research on Cancer, 150 Cours Albert-Thomas, 69372 Lyon Cedex 08, France Norman Breslow

(Chairman, IARC Fellowships Selection Committee)

Department of Biostatistics, UW.H656,

University of Washington, Box 357232,

Seattle, Washington 98195, USA 